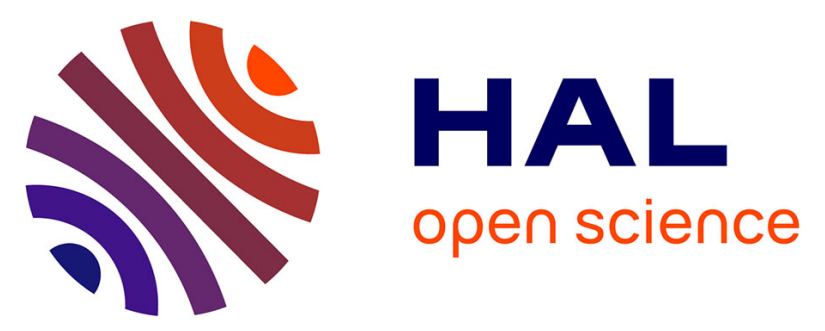

\title{
Polycrystal modelling of fatigue: pre-hardening and surface roughness effects on damage initiation for $304 \mathrm{~L}$ stainless steel \\ Anne Le Pécheur, Francois Curtit, Michel Clavel, Jean-Michel Stephan, Colette Rey, Philippe Bompard
}

\section{To cite this version:}

Anne Le Pécheur, Francois Curtit, Michel Clavel, Jean-Michel Stephan, Colette Rey, et al.. Polycrystal modelling of fatigue: pre-hardening and surface roughness effects on damage initiation for 304L stainless steel. International Journal of Fatigue, 2012, 45, pp.48-60. 10.1016/j.ijfatigue.2012.05.016 . hal-00771339

\section{HAL Id: hal-00771339 \\ https://hal.science/hal-00771339}

Submitted on 8 Jan 2013

HAL is a multi-disciplinary open access archive for the deposit and dissemination of scientific research documents, whether they are published or not. The documents may come from teaching and research institutions in France or abroad, or from public or private research centers.
L'archive ouverte pluridisciplinaire HAL, est destinée au dépôt et à la diffusion de documents scientifiques de niveau recherche, publiés ou non, émanant des établissements d'enseignement et de recherche français ou étrangers, des laboratoires publics ou privés. 


\title{
Polycrystal modelling of fatigue: pre-hardening and surface roughness effects on damage initiation for 304L stainless steel
}

IJFat 452012 48-60

\author{
A. Le Pécheur ${ }^{\mathrm{a}, \mathrm{b}, \mathrm{c}}$, F. Curtit ${ }^{\mathrm{b}}$, M. Clavel $^{\mathrm{a}}$, J.M. Stephan ${ }^{\mathrm{b}}$, C. Rey ${ }^{\mathrm{a}}$, Ph. Bompard ${ }^{\mathrm{a}}$ \\ ${ }^{\text {a }}$ Laboratoire MSSMat, UMR 8579 CNRS, Ecole Centrale Paris, Grande voie des Vignes, \\ 92295 Châtenay-Malabry Cedex France \\ ${ }^{\mathrm{b}}$ Département MMC, EDF R\&D, Site des Renardières, Route de Sens Ecuelles, 77250 Moret- \\ sur-Loing, France
}

\begin{abstract}
The 304L stainless steel is a major component of residual heat removal circuits of pressurized water reactors (PWR).The main purpose of this study is to understand the risk of thermal fatigue damage resulting from the machining of the 304L steel pipes inner surface (prehardening gradient, residual stresses and scratches), at the scale of the microstructure. This work is based on previous results obtained for pipe specimens thanks to a macroscopic elastovisco-plastic model. Applied to the pipe specimens, this modelling showed that a thermal loading with temperature gradient, induced a cyclic non linear biaxial loading at the inner surface of the pipe. In this paper, a polycrystal plasticity model, implemented in a Finite Element (FE) code, is adapted to cyclic loading. An elementary volume (3D aggregate), representing the inner surface and sub-surface of the 304L steel tube, is built from successive polishings and orientation mappings thanks to an Electron Back Scattering Diffraction method. At the grain scale, the polycrystal model is used as a "numerical microscope" to compute the local mechanical fields. Different fatigue criteria are tested to determine their sensitivity to surface properties (roughness, residual stress and pre-hardening) and to the microstructure of the material (crystallographic orientation and grain size). Pre-hardening leads to a lower and more homogeneous distribution of local strain amplitudes in the aggregate, but slightly higher stresses when compared to initial material without hardening. By contrast, surface roughness leads to large localized strain and stress fields in grains located at the bottom of scratches. To determine the surface micro-structural "hot spots" features and to test the sensitivity of different surface conditions, three different fatigue criteria (MansonCoffin, Fatemi-Socie and Dissipated Energy criteria) have been computed. We point out that the pre-hardening may have a complex effect on fatigue resistance, since it reduces local plastic strain amplitudes, but increases local stresses. Moreover, the pre-hardening has a positive effect on fatigue since it delays damage initiation. By contrast, the surface roughness leads to a negative effect. However, we have shown that the three different fatigue criteria do not deliver similar quantitative predictions. Relevant criteria for high cycle fatigue, such as stress based criteria, are not considered in this paper, since the thermal loading used for computation is large enough to reduce cyclic plastic strain straining within all grains of 304L pipe inner surface for midlife of experiments.
\end{abstract}

Keywords: thermal fatigue, fatigue criteria, polycrystal modelling, surface conditions, 304L stainless steel.

\section{Introduction}


To understand the risk of thermal fatigue damage resulting from the machining of austenitic stainless steel pipes inner surface (pre-hardening gradient, residual stresses and scratches), experimental tests on pipe specimens were developed respectively by Centre d'Energie Atomique CEA (FAT3D) [1, 2] and Electricité de France EDF (INTHERPOL) [3]. This paper deals with INTHERPOL tests, where pipe specimens are submitted to fatigue thermal loading and temperature gradients. In previous papers [4 to 7], pre-hardening and residual stresses due to machining were pointed out at the inner surface of the pipes. Thanks to a macroscopic elasto-visco-plastic cyclic model [7], computations showed that the inner surface of the pipe specimens was submitted to a non proportional biaxial loading. A new study of the material is required at the level of the grains, because fatigue crack initiation depends on local mechanical fields at the scale of the scratches. In this paper, a polycrystal modelling is adapted to cyclic plasticity by introducing a kinematic hardening. Previously computed through the macroscopic model [7], a biaxial loading is applied to a Representative Volume Element (RVE). This RVE, designed as a three dimensional aggregate, is built from successive Electron Back Scattering Diffraction (EBSD) mappings of an actual 304L material. In order to represent a RVE at the inner and subsurface of the pipe specimens, a specific loading is used to create a pre-hardening gradient and residual stresses in the designed aggregates.

Coupled to Finite Element method, polycrystal modellings are efficient tools to assess the evolution of local strain and stress as well as the rotation fields in polycrystalline two dimensional (2D) and three dimensional (3D) aggregates submitted to monotonic and cyclic loadings. Most of these approaches were based on a large kinematic formulation proposed by Asaro et al [8 to 10], Pierce et al [11] and Needleman et al [12]. The increasing capability of computers enabled to investigate more and more complex mechanical behaviours and more elaborated microstructures. Crystal plasticity models were used by different authors to assess micro-mechanical as well as macro-mechanical behaviours of materials submitted to large deformations and different loading paths. Texture formation [13 to 19] and localization of local strain and stress fields within the grains [20 to 27] were widely investigated. In the ten last years, damage initiation was linked to micromechanical behaviour [28 to 30]. Grain size effect was introduced into constitutive laws thanks to necessary geometrical dislocations related to lattice curvature [31 to 37 ].

Recently, constitutive laws were developed to model cyclic deformation at macroscopic and microscopic scales [38 to 45]. A paper review of the different proposed polycrystalline constitutive laws and models was published by Roter et al [46].

This paper is divided into 6 sections. Section 2 gives a short summary of the results obtained by Le Pécheur et al [7] on the macroscopic experiments and modelling of INTHERPOL pipe specimens. Their results are used as input data in section 5. Section 3 of this work is devoted to the polycrystal model description. Identification of the material parameters and the validation of the model are given in section 4 . Section 5 describes the simulated local stress and strain fields within the aggregates submitted to the non linear biaxial loading used in section 2. In section 6, different damage criteria are tested to determine the relative weight of the different parameters on fatigue life, such as microstructure, pre-hardening gradient due to pre-straining and surface roughness. The paper is closed by a discussion and a conclusion (section 7).

\section{INTHERPOL tests.}

This section gives a short summary of the mains results obtained by Le Pécheur et al [7] on INTHERPOL pipe specimens. Tensile tests were carried out using strain gauges to measure the elastic properties of the material. Tensile tests, performed on differently oriented 
specimens, showed negligible differences of the elasto-visco-plastic properties and revealed no deformation texture. Fatigue tests were carried out on 304L pipe sections (300 mm length, $10 \mathrm{~mm}$ thickness). Controlled thermal cycles $\left(120{ }^{\circ} \mathrm{C}\right.$ amplitude, $5 \mathrm{~s}$ to $8 \mathrm{~s}$ period) were applied to a $70 \mathrm{~mm}$ wide sector of the internal surface of the specimen. Three surface finishes were respectively tested: raw, brushed and polished. During the tests, temperature evolutions were recorded by thermocouples and used as input data for the macroscopic model. Experimental investigations (Transmission Electron Microscope, micro-hardness), performed on a pipe specimen, revealed a large work-hardening gradient ( $300 \mu \mathrm{m}$ deep) under the inner surface. This work-hardening corresponded to gradients of yield strength and dislocation density. Input data for the mechanical behaviour (macroscopic model and the polycrystal model) were obtained through fatigue tests performed on cylindrical specimens $(8 \mathrm{~mm}$ diameter and $18 \mathrm{~mm}$ gauge length) at $20^{\circ} \mathrm{C}$ and $300^{\circ} \mathrm{C}$ under different strain rates. Some of the cylindrical specimens were pre-hardened by $13.6 \%$ tensile tests prior to fatigue. Such hardening amount gave the same micro-hardness value to the cylindrical specimens as well as the pipe specimen inner surface. The fatigue curves are given on Fig.1a and Fig.1c. Our purpose is to investigate the cyclic stabilized domain at mid life cycle number $\mathrm{N}=\mathrm{N}_{\mathrm{f}} / 2$, where $\mathrm{N}_{\mathrm{f}}$ corresponded to a $25 \%$ decrease of the maximal stress (i.e. half fatigue life). The veins and channels dislocation arrangement observed for $\mathrm{N}_{\mathrm{f}} / 2$ (Fig.1b) is a characteristic of low stacking fault energy materials. The high strain amplitude fatigue curve $( \pm 0.7 \%)$ will not be considered in this paper, since high strain amplitudes are out of the scope of INTHERPOL experiments and Residual Heat Removal circuit applications.
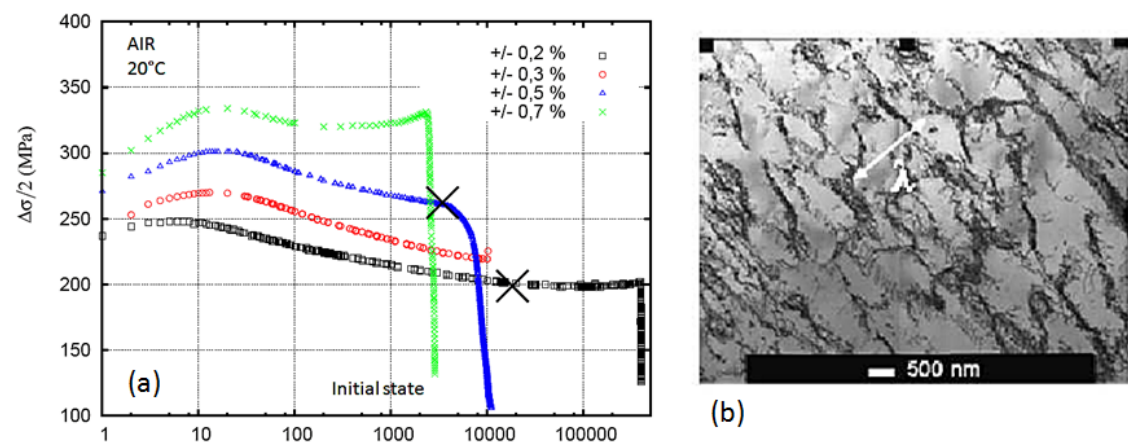

(b)

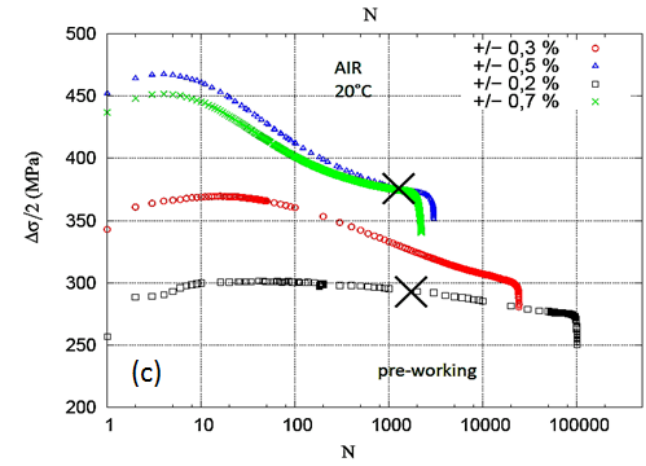

Fig.1. Fatigue test curves (strain rate $410^{-3} \mathrm{~s}^{1}$ ). (a) Initial material, (b) Dislocation pattern for $\mathrm{N}_{\mathrm{f}} / 2$, (c) prehardened material. The $X$ symbols correspond to $\mathrm{N}_{\mathrm{f}} / 2$, for the two strain amplitudes which were considered for model identification. $\lambda$ is the average distance between the dislocation walls.

As the scratches depth and width of the inner surface are comparable to grain size, fatigue damage initiation simulations have to be performed via a polycrystal model. Input data and especially the applied strain loading are obtained through our macroscopic modelling with pre- hardening memory effect implemented in a finite element code (EDF code-Aster@) [7]. Finite Element simulations, performed on the inner surface of pipe specimens showed a cyclic shakedown and a ratcheting effect which both ended into stabilized bi-axial cycles after 40 
numerical cycles. The computed cyclic axial and tangential internal stresses (Fig.7) were periodic but slightly non symmetric and non proportional.

\section{Polycrystal model and polycrystal 3D aggregate}

\subsection{Polycrystal model}

The used polycrystal plasticity model [20, 24, 25, 29] was developed in the framework of large transformations (small elastic distortion but large lattice rotation) proposed by Asaro et al [8 to 12] and was implemented in the Abaqus ${ }^{\circledR}$ finite element code, using an UMAT User Subroutine.

The kinematic is based on the velocity gradient $\tilde{L}$ which is decomposed additively [11] into an elastic part $\tilde{L}^{e}$ and a plastic part $\tilde{L}^{p}: \tilde{L}=\tilde{L}^{e}+\tilde{L}^{p}$, with $\tilde{L}^{e}=\dot{F}^{e} \tilde{F}^{e-1}$ and $\widetilde{L}^{p}=\tilde{F}^{p} \tilde{F}^{p-1}$.

$\tilde{F}^{e}$ and $\tilde{F}^{p}$ are the gradient of the transformation $\tilde{F}=\tilde{F}^{e} \tilde{F}^{p}$

We assume that elastic strain field $\tilde{\varepsilon}^{e}$ is small, so that $\tilde{F}^{e}=\left(1+\tilde{\varepsilon}^{e}\right)$.

The symmetric part of the velocity gradient tensor is given by:

with

$$
\widetilde{D}=\widetilde{D}^{e}+\widetilde{D}^{p}
$$

$$
\widetilde{D}^{p}=\sum_{s} \dot{\gamma}^{s}\left\{\vec{g}^{s} \otimes_{s} \vec{n}^{s}\right\} \text { and } \widetilde{D}^{e} \approx \dot{\tilde{\varepsilon}}^{e}
$$

where $\dot{\epsilon}^{e}$ is the elastic strain rate (small deformation). $\vec{g}^{s}$ and $\vec{n}^{s}$ are respectively the glide direction and the normal to the glide plane of the glide system (s). $\dot{\gamma}^{s}$ is the glide rate on the system (s) in the current (deformed) configuration.

The skew symmetric part of the velocity tensor is given by:

$$
\widetilde{W}=\widetilde{W}^{e}+\widetilde{W}^{p}
$$

where $\widetilde{W}^{e}$ is the lattice spin tensor and $\widetilde{W}^{p}=\sum_{S} \dot{\gamma}^{s}\left\{\vec{g}^{s} \otimes_{A} \vec{n}^{s}\right\}$.

$\otimes_{\mathrm{S}}$ and $\otimes_{\mathrm{A}}$ are respectively the symmetric and skew-symmetric parts of the tensorial product.

The rate form of the constitutive equation couples the elastic behaviour with the flow theory of plasticity through the Jaumann rate tensor $\tilde{\tau}^{*}$ of the $\tilde{\tau}$ Kirchhoff stress tensor, given by:

$$
\begin{gathered}
\tilde{\tau}^{*}=\dot{\tilde{\tau}}-\widetilde{W}^{e} \tilde{\tau}+\widetilde{\tau} \widetilde{W}^{e} \\
\tilde{\tau}^{*}=\widetilde{K}: \widetilde{D}-\sum_{s} \dot{\gamma}^{s} \widetilde{R}^{s}
\end{gathered}
$$

where $\widetilde{R}^{s}=\left[\widetilde{\widetilde{C}}: \widetilde{D}^{s}+\widetilde{W}^{s} \tilde{\tau}-\tilde{\tau} \widetilde{W}^{s}\right], \widetilde{D}^{s}=\left\{\vec{g}^{s} \otimes_{S} \vec{n}^{s}\right\}$ and $\widetilde{W}^{s}=\left\{\vec{g}^{s} \otimes_{A} \vec{n}^{s}\right\} . \widetilde{K}$ is a fourth rank tensor of elastic moduli. For small elastic strain, this tensor is identified with the usual fourth rank tensor of elastic moduli $\tilde{\tilde{C}}$. The time derivative of the Kirchhoff tensor $\dot{\tilde{\tau}}$ can express the resolved shear stress on system (s) [47].

Using the continuum theory of dislocations, the dislocation densities on each glide system are considered as internal variables. Single crystal plasticity laws proposed by Tabourot et al [48] are applied to each grain. Our polycrystal model is developed for face centered cubic structure (fcc) as well as body centered cubic (bcc) structures and two phase materials. In order to accurately describe the cyclic loading (i.e. Baushinger effect), a kinematic hardening is now introduced into this parent model. 
For fcc metals, the Schmid's criterion rules the activation of the 12 glide systems $\{110\}$ $<111>$. The kinematic hardening is introduced via a classical phenomenological "back stress" $x^{s}$. The criterion is given by:

$$
\left|\tau^{s}-x^{s}\right|=\tau_{c}^{s}
$$

where $\tau^{s}$ is the reduced shear stress on the glide plane (s), $x^{s}$ corresponds to the kinematic hardening and $\tau_{c}^{s}$ is the critical shear stress. The critical shear stress given by Eq.6 and Eq.7, is a function of the components $a^{s u}$ of the interaction matrix (forest hardening) between the systems (s) and (u). For fcc single crystal, the $12 \times 12$ interaction matrix is composed of four different terms. According to Franciosi et al [49], $a_{0}$ represents the interactions between similar dislocations, whereas $a_{1}$ described the interaction between collinear and orthogonal dislocations. Glissile junctions are given by $\mathrm{a}_{2}$ and Lomer-Cotrell junctions are given by $\mathrm{a}_{3}$. The components $a^{s u}$ do not depend on the sign of the dislocation glide and therefore on the sign of the shear loading on the dislocation plane. A hardening law is then introduced and gives the critical stress related to the dislocation densities on all systems:

$$
\tau_{c}^{s}=\tau_{0}^{s}+\mu b \sqrt{\sum_{u=1,12} a^{s u} \rho^{u}}=\sum_{u} h^{s u} \gamma^{u}
$$

where $\mu$ is the isotropic shear modulus, $b$ the norm of the Burgers vector, $\tau_{0}^{c}$ the lattice friction stress, $h^{s u}$ the component of the hardening matrix. $\rho^{u}$ and $\gamma^{u}$ are the dislocation density and the glide amplitude on system $(u)$ respectively. The $h^{\text {su }}$ matrix can describe an anisotropic hardening, which depends on the activated dislocations (i.e loading path). The kinematic hardening law considered here obeys to a non linear expression derived from a macroscopic law proposed by Armstrong and Fredericks [50].

$$
\dot{x}^{s}=C \dot{\gamma}^{s}-D\left|\dot{\gamma}^{s}\right| x^{s}
$$

where $\mathrm{C}$ and $\mathrm{D}$ are two material parameters.

The glide velocity $\dot{\gamma}^{s}$ is expressed with a classical visco-plastic potential based on the resolved shear stress and the critical shear stress for glide activating on system (s):

$$
\begin{aligned}
& \dot{\gamma}^{s}=\dot{\gamma}_{0}\left(\frac{\left|\tau^{s}-x^{s}\right|}{\tau_{c}^{s}}\right) \operatorname{sign}\left(\tau^{s}-x^{s}\right) \text { if }\left|\tau^{s}-x^{s}\right|>\tau_{c}^{s} \\
& \dot{\gamma}^{s}=0 \text { otherwise }
\end{aligned}
$$

where $\dot{\gamma}_{0}$ is a reference shear rate and $\mathrm{n}$ is a rate exponent.

The dislocation density evolution (Eq.10), is governed by a production term based on Orowan's relationship and is balanced by an annihilation term which takes into account the dynamic recovery during deformation.

$$
\left.\dot{\rho}^{s}=\frac{\left|\dot{\gamma}^{s}\right|}{b} \mid \frac{1}{D_{\text {grain }}}+\frac{\sqrt{\sum_{u \neq s} \rho^{u}}}{K}-g_{c} \rho^{s}\right]
$$


$D_{\text {grain }}$ is the grain size, $g_{c}$ is a material parameter related to an annihilation distance of dislocations. The second term in Eq.10 is the inverse of the average mean free path $L^{s}$ of the dislocations on the system (s). $\mathrm{K}$ is a material parameter related to the average mean free path on each glide system $L^{s}$. The evolution of $L^{s}$ comes from the evolution of the dislocation density on the other glide systems $(u)$ which intersect the glide plane $(s)$, through:

$$
L^{s}=K / \sqrt{\sum_{u \neq s} \rho^{u}}
$$

The equations are solved thanks to the scheme proposed by Peirce et al [11] using the forward gradient approximation [47], re-written to take into account the back stress of the constitutive law (Eq. 9).

The polycrystal model is implemented in Abaqus software package ${ }^{\circledR}$ using a User Subroutine (UMAT). The numerical scheme is an explicit forward gradient procedure which delivers a good accuracy and high integration speed. This method presents the drawback to impose very small time increments, but has the advantage to detect a progressive lattice reorientation (very small for fatigue tests) and the occurrence of new active glide systems. For such time increments, our small elastic strain assumption is valid. Dislocation densities, cumulated glide on the glide systems, total cumulated glide magnitude and dissipated energy are respectively computed at each increment and for each Gauss point. The constitutive law of this polycrystal model can describe plastic anisotropy, which is linked to the number and orientation of the activated glide systems [24]. The chosen "back stress" tensor $\tilde{x}$ describes the strain incompatibilities between neighbouring grains and long distance dislocation interaction due to pile up formation [51].

\subsection{Three dimensional aggregate mapping and meshing of a 304L polycrystal}

To accurately compute the local mechanical fields at the grain scale, a representative elementary volume (3D aggregate) was designed. Using successive mechanical polishings and EBSD orientations of a 304L real material, the aggregate is realized with sixteen successive orientation maps (Fig. 2). An extrusion of $25 \mu \mathrm{m}$ thickness is applied to each layer. Each extrusion corresponds to 3 Finite Element layers owing the same orientation. For an average grain size of about $50 \mu \mathrm{m}$, the final dimension of the aggregate is $400 \mathrm{x} 400 \mathrm{x} 400 \mu \mathrm{m}^{3}$.

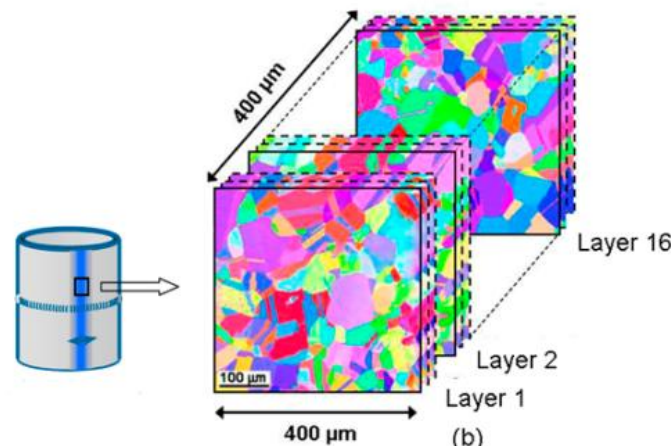

(b)

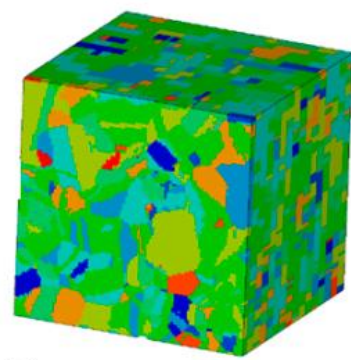

(c)

Fig.2. Construction and meshing of the 3D aggregate. (a) pipe specimen, (b) pile up of EBSD maps, (c) final 3D aggregate.

The 3D Finite Element (FE) meshing is thus derived from the square grid of the 2D EBSD obtained with a $1 \mu \mathrm{m}$ resolution. The FE meshing is built with cubic C3D8R elements (linear reduced integration). An element of the meshing corresponds to $12 \times 12 \times 12 \mu \mathrm{m}^{3}$. 


\section{Identification of the parameters of the constitutive laws and validation of the model}

4.1 Identification of the parameters of the constitutive laws

To separate the effects of microstructure and of pre-hardening, two cases are examined: an aggregate without pre-hardening (initial aggregate AG1), an aggregate with pre-hardening (aggregate AG2). In a further step (see section 6), this second aggregate will receive different surface roughness types (named aggregates AG3a and AG3b), in order to test the influence of surface micro-geometry on damage initiation undergoing thermal loading. Aggregate calculations requiring huge computer time and needing large computer memory, the identification is thus only performed on stabilized cyclic behaviour, at midlife time of the fatigue curve. The parameters $n, K, g_{c}, C, D$ are identified from experimental curves (tensile curves and stabilized uniaxial cyclic mechanical curves) and by an inverse method [29]. The elastic constants and the hardening matrix type are obtained from literature. The initial dislocation density is measured by TEM. The $a^{\text {su }}$ hardening coefficients depend on deformation rate and microstructure but, in our study, they are assumed constant with deformation. The boundary conditions are given on Fig.3a. The parameters identification is performed on stabilized curves corresponding to the half fatigue life of two experimental fatigue curves $( \pm 0.2 \%$ and $\pm 0.5 \%)$.

\subsubsection{Aggregate without pre- hardening}

The parameters used for the computation of the local mechanical fields are given in Table 1. The obtained numerical curves are compared to experimental curves on Fig.3b and Fig.3c.

\begin{tabular}{llllllll}
\hline $\begin{array}{l}C_{11} \\
(M P a)\end{array}$ & $\begin{array}{l}C_{12} \\
(M P a)\end{array}$ & $\begin{array}{l}C_{44} \\
(M P a)\end{array}$ & $\begin{array}{l}\rho_{0} \\
\left(m^{-2}\right)\end{array}$ & $\begin{array}{l}b \\
(m)\end{array}$ & $\begin{array}{l}\tau_{0} \\
(M P a)\end{array}$ & $\begin{array}{l}\dot{\gamma}_{0} \\
\left(s^{-1}\right)\end{array}$ & $\begin{array}{l}n \\
(-)\end{array}$ \\
\hline 261200 & 112000 & 74600 & $9.10^{12}$ & $2.539 .10^{-10}$ & 10 & $1.10^{-5}$ & 49 \\
\hline$K$ & $g_{c}$ & $\begin{array}{l}a_{0} \\
(-)\end{array}$ & $\begin{array}{l}a_{1} \\
(m)\end{array}$ & $\begin{array}{l}a_{2} \\
(-)\end{array}$ & $\begin{array}{l}a_{3} \\
(-)\end{array}$ & $\begin{array}{l}C \\
(-)\end{array}$ & $\begin{array}{l}D \\
(-)\end{array}$ \\
\hline 1 & $150.10^{-9}$ & 0.045 & 0.625 & 0.137 & 0.122 & 15300 & 430 \\
\hline
\end{tabular}

Table 1. Identified parameters of the polycrystal model without pre-straining.

\subsubsection{Aggregate with pre-hardening}

Identification of the parameters for such pre-deformed material is performed on a dedicated first aggregate, $13.6 \%$ uniformly pre-strained in tension. This monotonic pre-hardening introduces residual stresses in the material and a modification of the dislocation substructure. The austenitic steel 304L exhibiting a strong memory effect due to a more planar and entangled dislocation substructure, the parameters: $\tau_{0}, K, g_{c}, \eta, C$ and $D$ have to be modified (Table 2):

\begin{tabular}{|c|c|c|c|}
\hline \multicolumn{2}{|c|}{ Constitutive laws } & \multicolumn{2}{|c|}{$\begin{array}{l}\text { Kinematic } \\
\text { hardening }\end{array}$} \\
\hline$\tau_{0}(\mathrm{MPa}) \quad K$ & $g_{c}(\mathrm{~m})$ & $C$ & $D$ \\
\hline 20 & $8.10^{-9}$ & 30000 & 430 \\
\hline
\end{tabular}

Table 2. Parameters of the polycrystal model with pre-straining. 
4.2 Numerical and experimental curves comparison

AG1 and AG2 experimental and numerical stabilized cycles are compared for $\mathrm{N}=\mathrm{N}_{\mathrm{f}} / 2$

(Fig.3b). A good agreement is observed between these curves, whatever the applied strains.

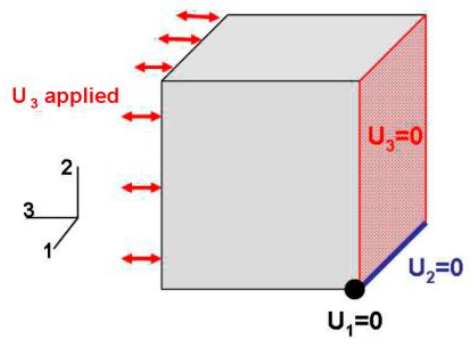

(a)
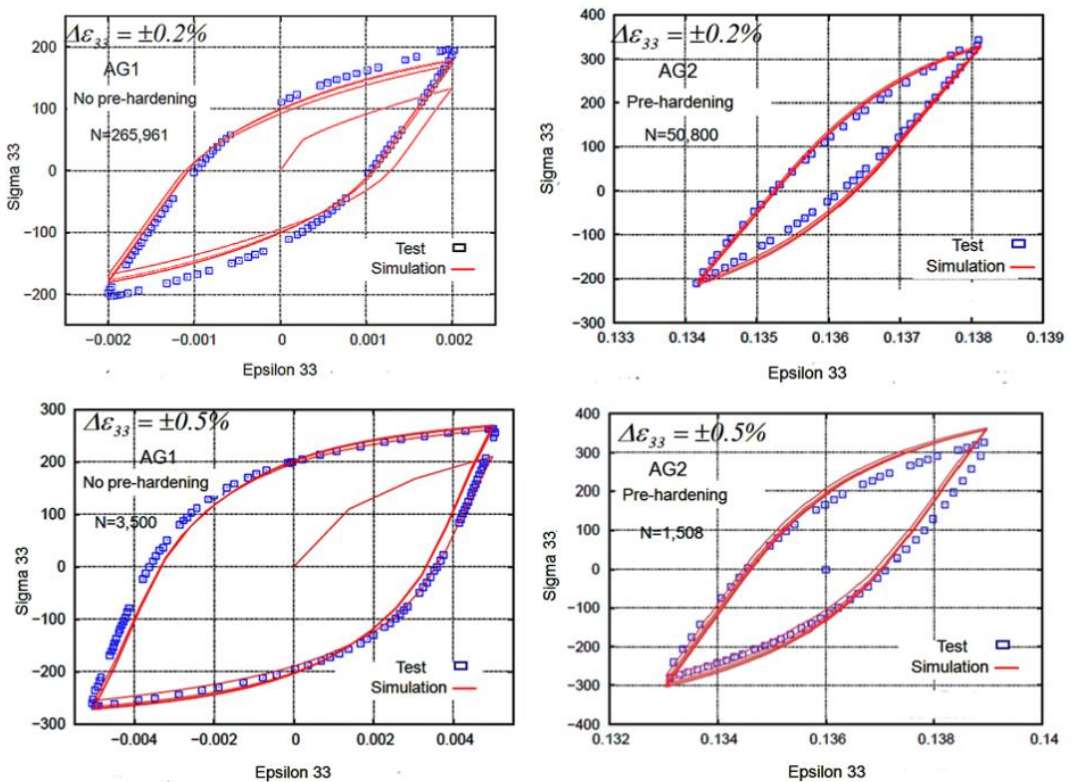

(b)

Fig.3. (a) Boundary conditions (b) Stabilized cycle in tension-compression: numerical and experimental curves at $\mathrm{N}_{\mathrm{f}} / 2$ for $\mathrm{AG} 1$ and $\mathrm{AG} 2$.

To validate our model, experimental and numerical uniaxial tensile curves are compared on Fig.4.

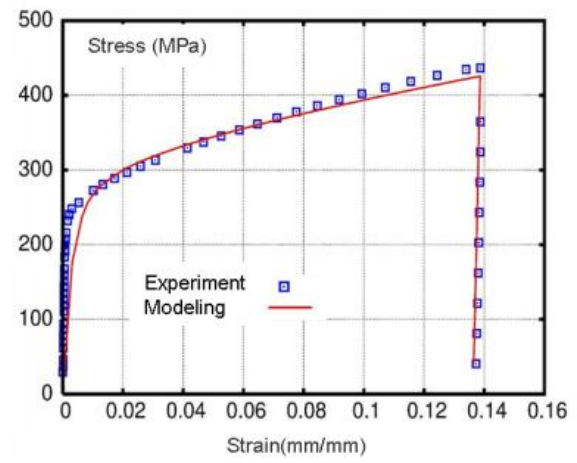

Fig.4. Comparison of experimental and numerical tensile curves

Fig. 4 shows that the micro-plasticity domain is not accurately described by our model and that the numerical hardening slope is slightly lower than the experimental one. However, the 
elastic unloading is correctly described. This means that, for tensile tests, glide systems are activated sooner in our simulation than in experiment and that the dislocation density evolution is weaker than expected.

To sum up our results for the softening stage, the fatigue life shows a plateau, followed by a final steep hardening decrease induced by macro-cracks in the cylindrical specimens (Fig.1a and Fig.1b). Indentified on midlife stabilized curves, the polycrystal model is limited to the description of the stabilized plateau regime. Further improvements [52 to 55] have shown, that the whole hardening-softening curve can be described at the cost of longer computing time and larger storage memory.

\section{Simulation of a non proportional biaxial fatigue loading}

To compute the local mechanical fields in an aggregate located at the inner free surface of the thermal fatigue pipe specimen, pre-hardening gradient and residual stresses are introduced in the aggregate thanks to a new hereafter detailed method (Fig.5).

\subsection{Gradient of pre-hardening}

To introduce the effect of the pre-strain gradient, the shape of the aggregate is changed from cubic to trapezoidal. A displacement $\mathrm{U} 3$, linear function of $\mathrm{x}_{2}$, is applied to the surface normal to $\overrightarrow{3}$ of this new aggregate. $\mathrm{U} 1=0$ is applied to the surface normal to $\vec{l}$. The pyramidal aggregate is submitted to a gradient of applied strain reaching 30\% at the top and $0 \%$ at the bottom (i.e. $15 \%$ at mid depth of the pre-strained layer). As soon as the shape of the trapezoidal aggregate turns cubic (thanks to the plasticity), the loading is dropped to 0 . Using the polycrystal model, the calculation of residual strains gives: $-0.003<\varepsilon_{33}<0.31$ and $-0.1<\varepsilon_{11}<0.17$ (Fig.5). The resulting microstructure presents a gradient of hardening corresponding to the inner surface of 304L pipes used for INTHERPOL experiments. For this pre-hardened aggregate, the model parameters correspond to Table 1 and Table 2.

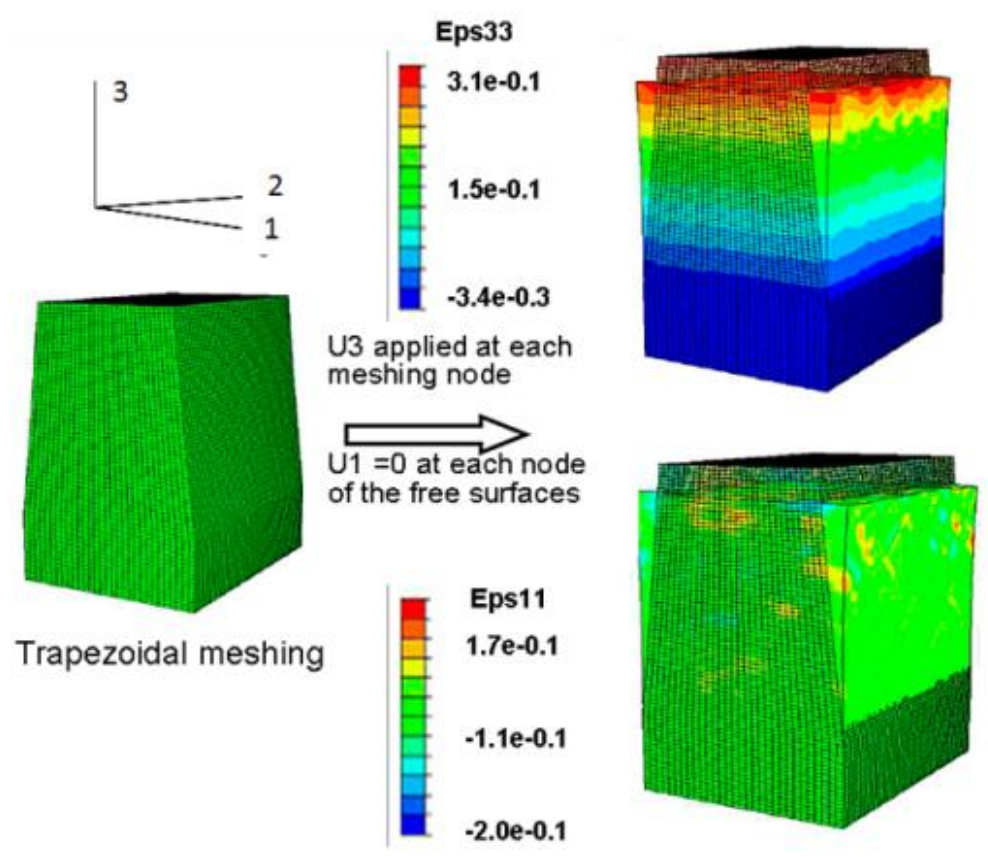

Fig.5. Sketch illustrating the method used to obtain a gradient of pre-strain hardening. 


\subsection{Loading path}

According to the results issued from FE simulation of macroscopic thermal fatigue test [7], the aggregates were submitted to a non proportional biaxial mechanical loading. The boundary conditions and the biaxial loading are given on Fig 6a. In order to provide noticeable results for thermal loading effects, while keeping representative pre-hardening gradient and scratch morphologies, the applied strain amplitude given by the macroscopic model (Fig.6b) has been multiplied by a factor 2 . The applied non proportional loading corresponded to the points of the curves $\left(\varepsilon_{11} / t\right)$ and $\left(\varepsilon_{33} / t\right)$, computed in a central point of the internal surface of the pipe specimen. This loading was given by the applied strains $\varepsilon_{11}$ and $\varepsilon_{33}$, respectively ranging between (-0.005 and 0.02) and between (0 and 0.0042). During the first cycles, the strains were progressively imposed through a proportional quasi static monotonic loading. Then twelve cycles were computed, leading to the cyclic stabilized state corresponding to midlife of the specimens.

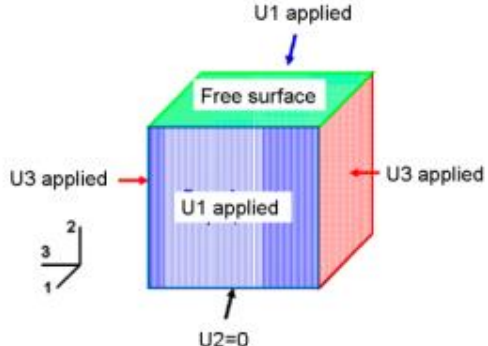

(a)

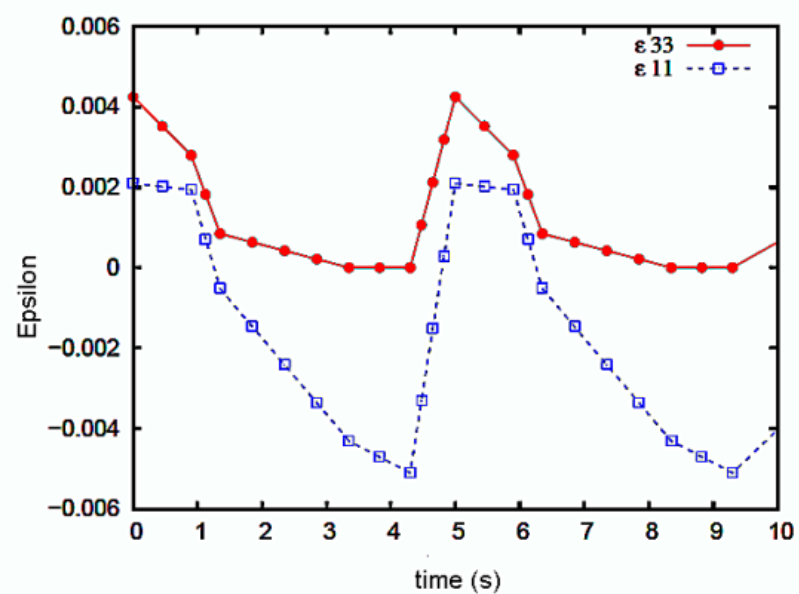

(b)

Fig.6. (a) Aggregate boundary conditions. (b) Biaxial loading path computed from macroscopic simulation on the pipe specimen and applied to the aggregates. This strain loading is twice the INTHERPOL loading.

5.3 Computation of average stabilized cyclic curves and local mechanical fields

Two new aggregates (AG3a and AG3b) presenting pre-strained gradient and two different surfaces roughnesses were also studied. The results being similar between AG3a and AG3b, only AG3a is presented in this section.

Identification of the stabilized cycle was performed on a dual processor Dell Multicore 3.2G. Computation time was rather long: for each aggregate, the CPU time is $510^{5} \mathrm{~s}$ and the cycle duration was $1.310^{5} \mathrm{~s}$. Simulation of the local stress and strain fields within the aggregates, was performed with Abaqus software package ${ }^{\circledR}$, thanks to our UMAT User subroutine.

\subsubsection{Stabilized cyclic curves}

To compare aggregate results with macroscopic FE results, the average values $\langle\sigma\rangle$ and $\langle\varepsilon\rangle$ are computed for AG1. The two cyclic curves $\langle\sigma\rangle$ versus $\langle\varepsilon\rangle$ do not significantly change after 3 to 5 cycles. But, to ensure that local stress and strain cyclic states are stabilized, the latter are computed up to 12 cycles. The averaged responses of the whole aggregate (Fig.7a and Fig.7b), show the same features as the mechanical responses given by the FE macroscopic 
model (Fig.7c) [7]. It should be reminded that the INTHERPOL biaxial strain loading being multiplied by a factor 2 , the non proportional stress-strain cycles are over evaluated by about the same factor. These results show the polycrystalline ability to correctly predict the behaviour of the material, even under a non proportional cyclic loading.

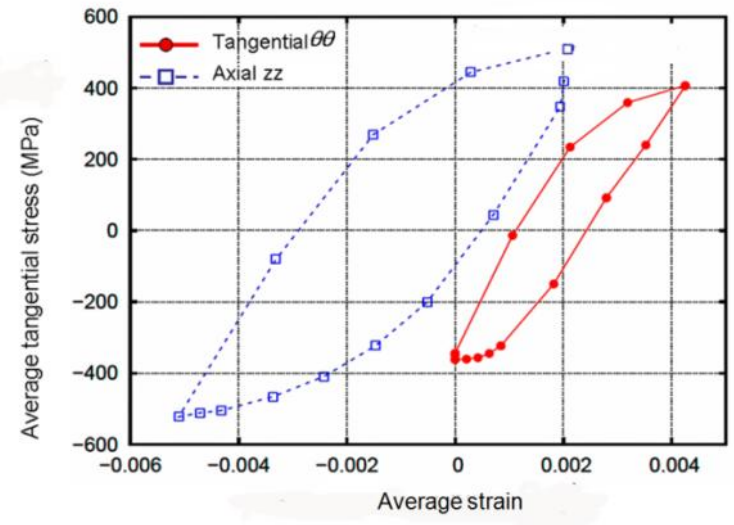

(a)

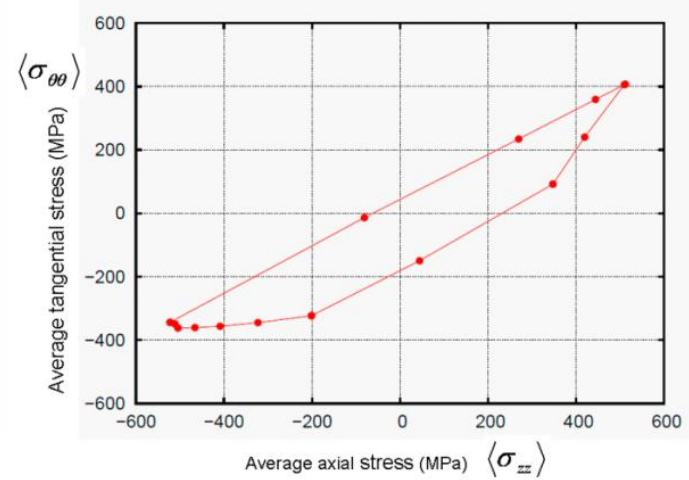

(b)

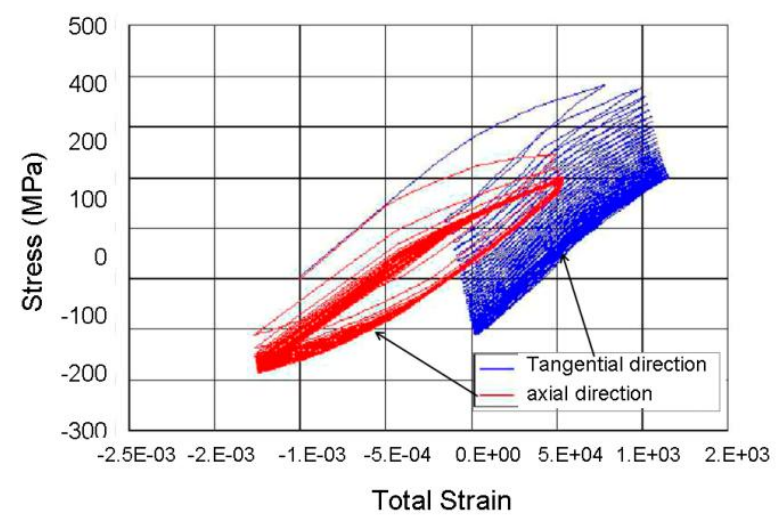

(c)

Fig.7. Mean cyclic behaviour of the aggregate after 12 cycles: (a) Numerical stabilized cyclic curves in tangential and axial direction; (b) tangential stress versus axial stress curve. $\overrightarrow{3}$ is parallel to the tangential axis $\vec{\theta}, \vec{l}$ is parallel to the axial axis $\vec{z}$ of the pipe specimen, (c) Tangential and axial cycles obtained by the macroscopic FE modelling on the inner surface of the pipe specimen (the colours are permuted).

\subsubsection{Simulation of the local mechanical fields}

To visualize the mechanical fields of interest for fatigue purpose, equivalent stress $\sigma^{e q}$ and equivalent strain $\varepsilon^{e q}$ mappings are considered: $\sigma^{e q}=\sqrt{3 / 2 s_{i j} s_{i j}}$ and $\varepsilon^{e q}=\sqrt{2 / 3 e_{i j} e_{i j}}$ where $\tilde{s}$ and $\tilde{e}$ are respectively the deviators of the Cauchy stress tensor and of the total strain tensor. It should be noted that the given plane maps are computed into the initial configuration after pre-straining but prior to cyclic loading. Nevertheless, cyclic displacements remain very small. The distribution of the equivalent strain and stress are respectively given in Fig. 8 and Fig.9. 


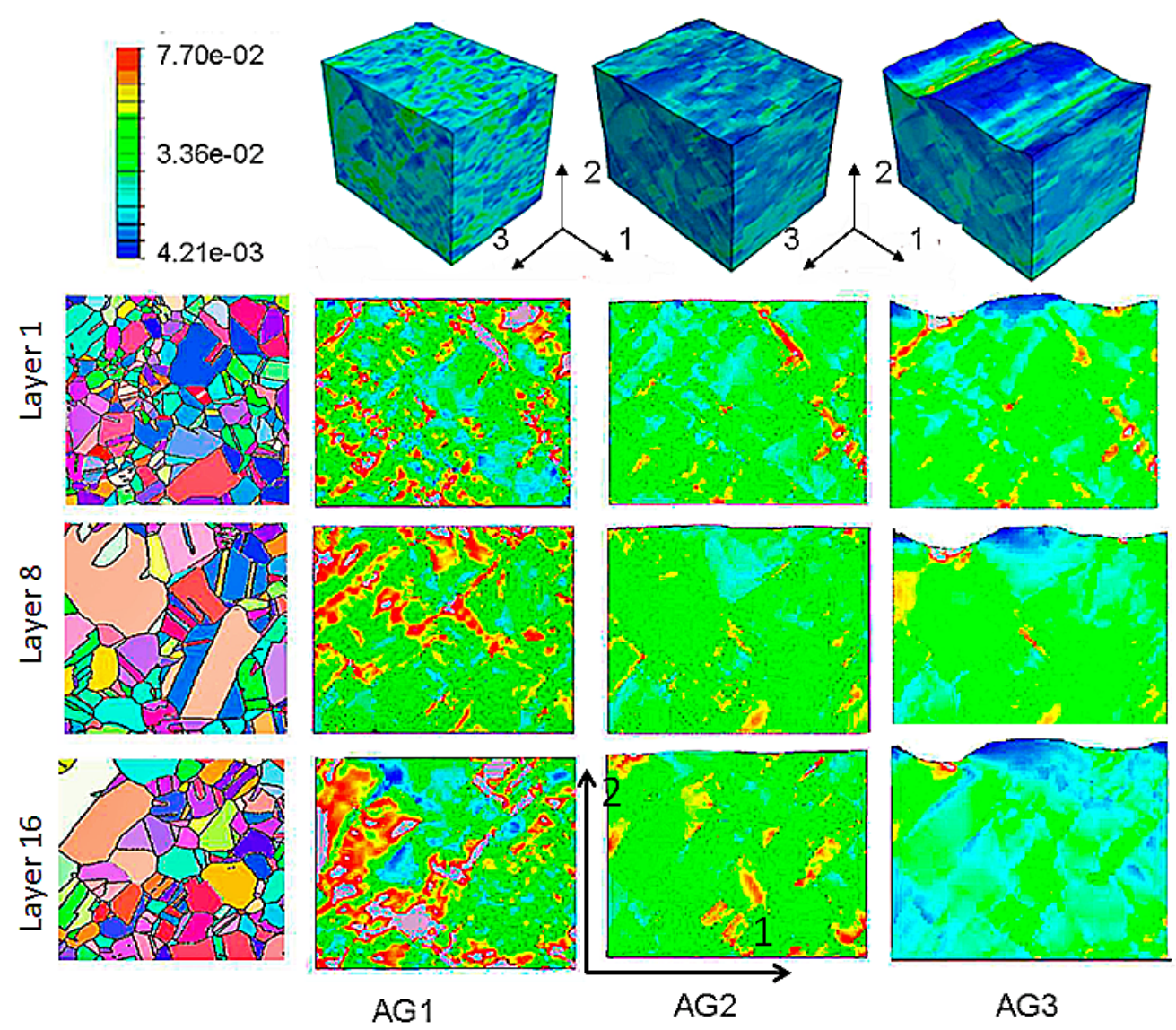

Fig.8. Equivalent strain localization for the 3 aggregates, AG1 initial microstructure, AG2 pre-strained microstructure, AG3 pre-strained microstructure and rough surface.

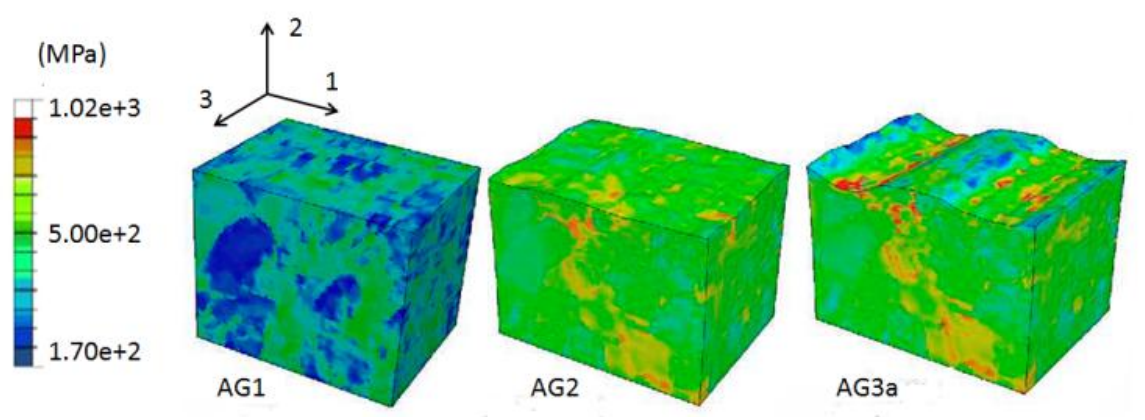

Fig.9. Equivalent stress localization for the 3 aggregates, AG1 initial microstructure, AG2 pre-strained microstructure, AG3 pre-strained microstructure and rough surface.

Fig. 8 and Fig.9 show that the different strain mappings, corresponding to different sections in the 3D microstructure, are dependent upon the local microstructure, but give the same qualitative information about the localization of strain and stress heterogeneities. For the initial aggregate AG1 (without pre-hardening) strain and stress fields are strongly inhomogeneous. These heterogeneities are composed of localization bands (in red on Fg.8) where the total equivalent strain can be up to a $7 \%$ amplitude. These short bands are two or three grain wide. AG2 and AG3 present more homogeneous strain fields and only few 
deformation bands within some grains. The strain localization mainly depends on microstructure and the scratches effects are limited to the first layer of grains.

The two aggregates AG2 and AG3 present identical stress localization within a band oriented at $45^{\circ}$ of the $\overrightarrow{2}$ axis, normal to the surface of the aggregate. Some Gauss points reach a 1,000 MPa equivalent stress, while the average axial and tangential stresses are about 400/500 MPa. The pre-hardening AG3 mapping (Fig.9) shows also high stress values in the first layer of grains. For AG2 and AG3, the level of the average local stresses $\sigma_{11}, \sigma_{33}$ is two times higher than for AG1.

Comparisons of the stress distribution curves of the different aggregates (Fig.10) clearly show that pre-straining increases the local stresses, but strongly reduces the plastic strain within the grains of AG2 and AG3 (Fig.8), possibly leading to a better fatigue resistance for stress controlled loading (lower strains) but not necessarily under strain controlled loadings (higher stresses). The surface roughness effect leads to higher stresses and deeper localization of plasticity at the bottom of scratches. For AG3, these high values, combined with the vicinity of highly stressed grains at the bottom of scratches, may enhance the stage I to stage II microcracking transition. These are relevant features for a decrease of high cycle fatigue resistance, compared to smoothly pre-strained specimens, as it could be obtained through brushing and polishing surfaces after machining.
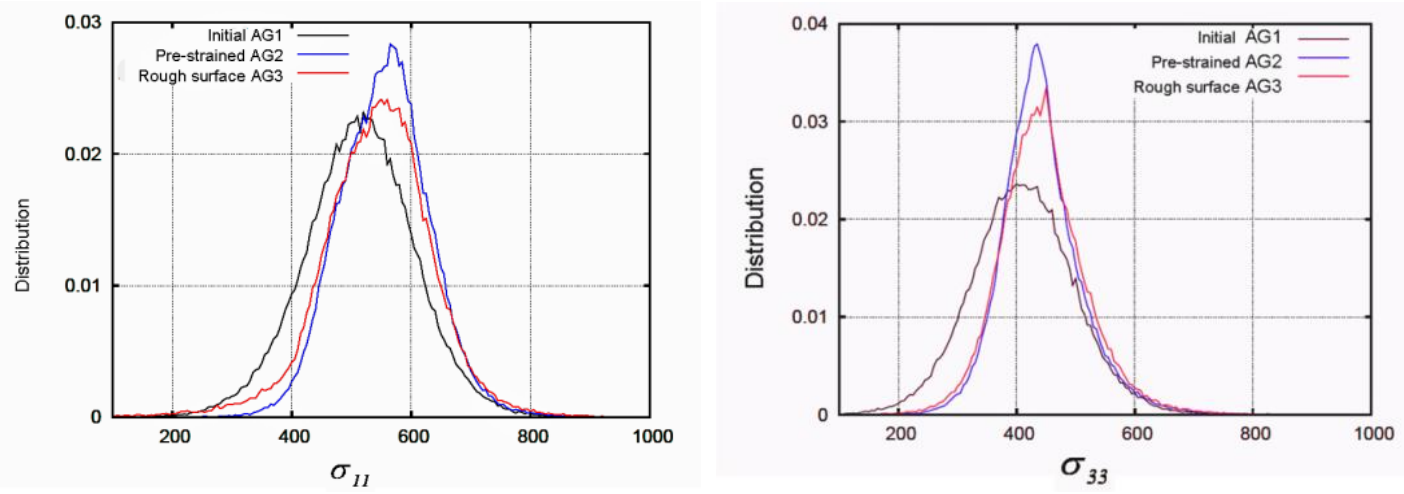

Fig.10. Distribution of $\sigma_{11}$ and $\sigma_{33}$ for the three aggregates AG1 (without pre-hardening), AG2 (with pre-hardening) and AG3 (pre-hardening and rough surface)

This rather simple polycrystal model is designed for an efficient computation of the local stabilized state. It can give a hint of the respective effects of strain hardening, microstructure and surface scratches on the RVE specimens, which can be hardly obtained from experiments on pipe specimens. The model cannot describe the whole fatigue curve. The dislocation density law (Eq. 10) cannot describe the dislocation microstructure evolution leading to large softening. It should be noted that some authors succeeded in describing the softening curves, thanks to an adapted "walls and channels Mughrabi type" microstructure implemented in a self consistent model $[52,53]$ and also in a more complex version of our model $[54,55]$. To reduce computation time, such an implementation, has not been introduced in this paper.

\section{Damage criteria}

In this section, the hereafter damage criteria are studied by focusing on their main parameter.

- The Manson Coffin fatigue criterion parameter, is based on the local cyclic equivalent plastic strain amplitude $\Delta \varepsilon_{e q}$ within grains. The main parameter is given by:

$$
F_{\text {MCeq }}=\Delta \varepsilon_{\text {eq }} / 2
$$


As a simplified approach, this parameter, relevant for low cycle fatigue, is used here at the grain scale.

- A "critical plane" fatigue criterion parameter, based on the local maximum shear strain amplitude $\Delta \gamma_{\max }$, modified for triaxiality amplitude $\chi$ :

$$
F_{C P}=\Delta \gamma_{\max }(1+\chi)
$$

$\Delta \gamma_{\max }$ is the maximum value of shear amplitude on all glide systems in each element of the meshing. $\chi=P_{\max } / \sigma_{e q}^{\max }$ is the tri-axial amplitude, $P_{\max }$ is the maximum hydrostatic pressure and $\sigma_{e q}^{\max }$ is the equivalent stress at the maximum of the stabilized cycle. This parameter is close to Fatemi Socie criterion parameter $[56,57]$ (using $\sigma_{N}$ normal stress to critical plane, instead of triaxiality $\chi$ ), and has been chosen for a better understanding of the effect of scratches.

- A “dissipated energy" fatigue criterion parameter, corrected for hydrostatic stress. It was first proposed by Park and Nelson [58 ], then modified by Aimable et al [59, 60] and Fissolo et al $[1,2]$ :

$$
F_{D E}=W^{p}+\alpha P_{\max }
$$

$W^{p}$ is the plastic work equal to the area of hysteresis loop of the stabilized cycle. $P_{\max }$ is the hydrostatic pressure at the maximum of the cycle. The material parameter $\alpha$ was identified on 304L specimens, through tensile-compression thermal fatigue tests performed with different triaxiality rates $[60,1,2]$. We choose a mean value corresponding to $\alpha=0.01$.

Four aggregates are analysed: AG1, AG2, AG3a and AG3b. AG3a and AG3b present similar pre-straining but have different surface roughnesses: raw (deep scratches) and brushed (smooth scratches) respectively. The results on AG3a and AG3b are only given when some differences happen at the vicinity of the surface.

6.1 Damage parameters results in the stabilized cyclic domain

The shear value $\Delta \gamma_{\max }$ and the dissipated energy $W^{P}$ are computed in each Gauss point of the FE meshing, thus the maximal values are easily detected in the maps.

The maps corresponding to $F_{M C e q}$ being equivalent to the maps presented Fig.8, only $F_{C P}$ and $F_{F D E}$ values are given on Fig.11 and Fig.12 respectively. 


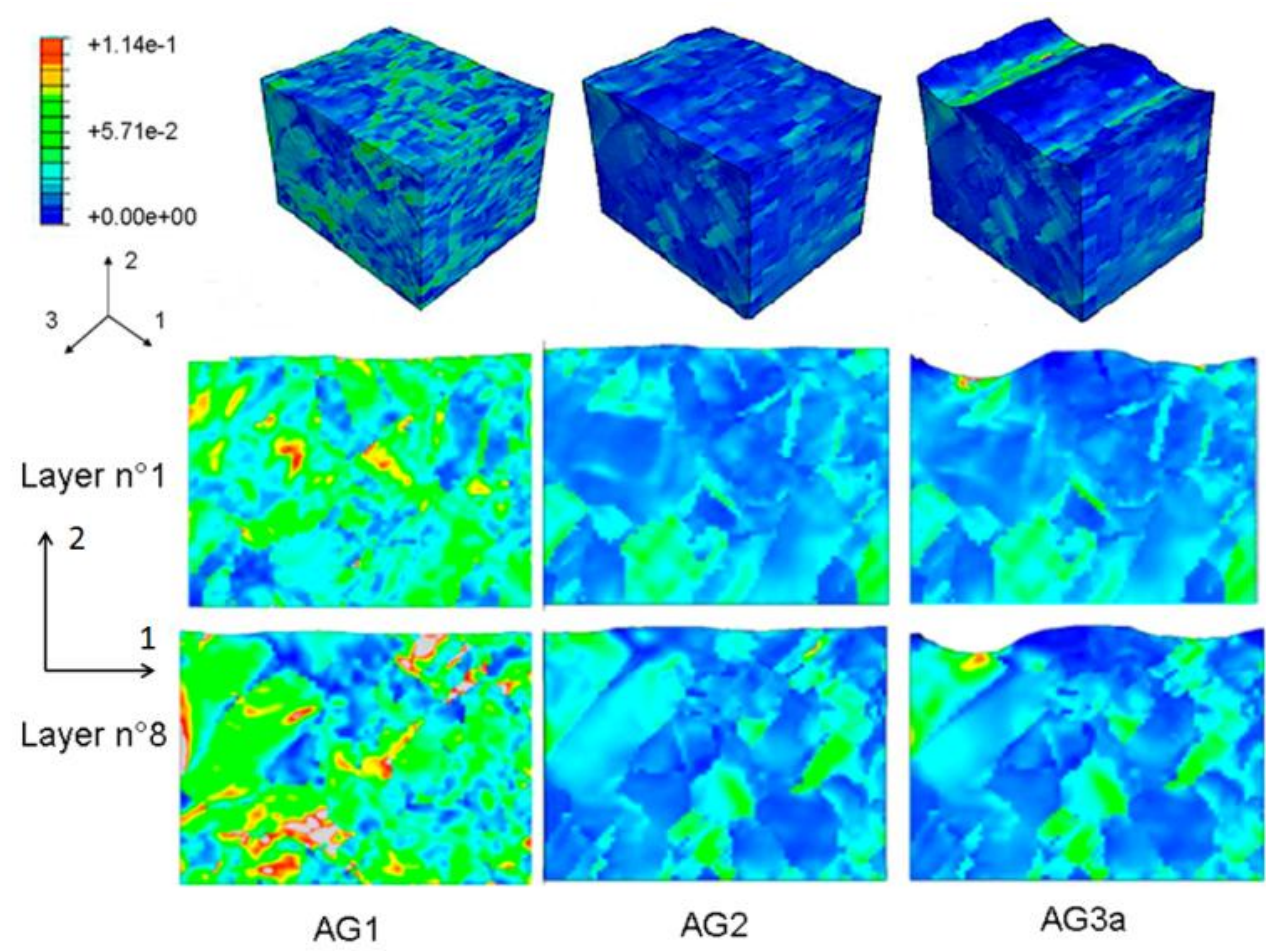

Fig.11. $F_{C P}=\Delta \gamma_{\max }(1+\chi)$ values. Top: whole 3D aggregates. Bottom: layers 1 and 8, normal to $\overrightarrow{3}$ tangential axis.
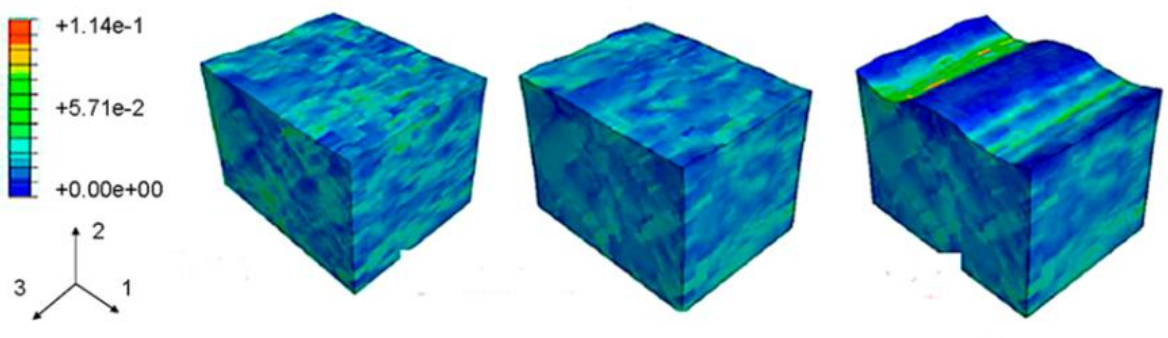

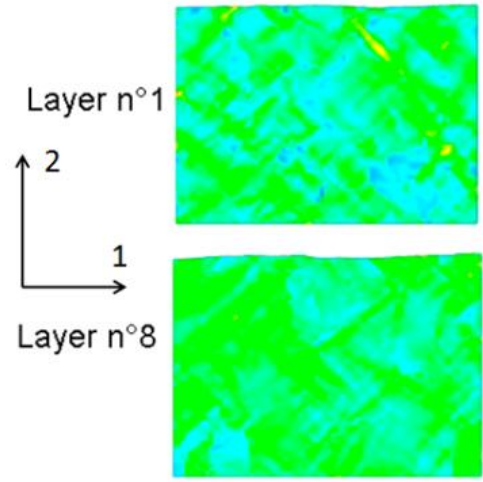

AG1
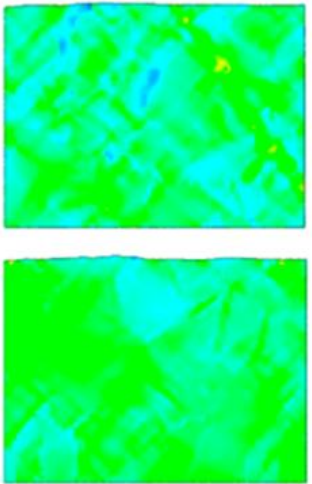

AG2
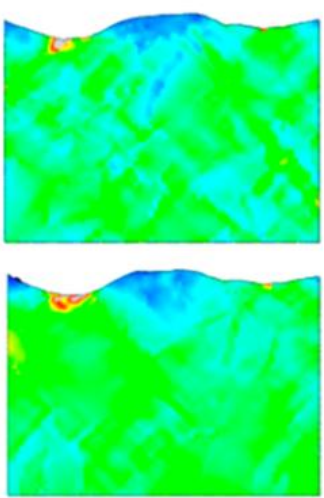

AG3a

Fig.12. $F_{D E}=W^{p}+\alpha P_{\max }$ values. Top: whole 3D aggregates. Bottom: layers 1 and 8 normal to $\overrightarrow{3}$ tangential axis.

For $F_{C P}$ criterion parameter, up to $11 \%$ of amplitude strain localization spots are revealed for AG1, though for AG2 and AG3, the maximum strain only reaches 3\%. According to this criterion, the maximum values, in the stabilized state, are more important for the initial 
aggregate than for the pre-hardened ones, except at the bottom scratch valleys. In itself, this result may delay damage initiation.

The $F_{D E}$ fatigue distribution (Fig.12) shows poor sensitivity to pre-hardening: AG1, AG2 and AG3a present the same strain distribution. Nevertheless, this parameter takes into account the surface finish effects.

The Manson Coffin and Critical Plane criteria parameters point out the opposite effects of pre-hardening and surface roughness. The two criteria reveal some weak differences within the bulk of the aggregates AG2 and AG3a, but present the same hot spots at the bottom of the scratches. According to these two criteria, pre-hardening should delay the microcracks formation in the stabilized cyclic domain, but cannot explain the decrease of the life time of the pre-hardened specimens. However, the fatigue life of the smoothly pre-strained specimens for low cycle test (Fig.1) is lower, compared to the initial 304L cylindrical specimen (factor 2 or 3), especially at low strain amplitude. This may suggest that higher stresses also promote microcrack openings and propagation from shear bands, leading to a global complex effect. Furthermore, strain controlled loadings should probably be more harmful than stress controlled loadings in the case of pre-hardened materials. By contrast, the Dissipated Energy parameters show a lower sensitivity to pre-hardening effects: the damage in AG1, AG2 and AG3a are very close, except at the hot spots at the bottom scratches valleys of AG3a. Owing to the rather high loading used for this simulation and subsequent cyclic plasticity within all grains, stress based fatigue criteria have not been studied in this paper, although the latter criteria parameters are more suited for high cycle fatigue regimes.

\subsection{Effect of roughness profiles}

The consequences of the two different roughness profiles (AG3a and AG3b) on the three criteria are simulated. In this section, to focus on strain based approaches, we only study the Critical Plane and Dissipated Energy parameters, both being corrected for triaxiality or hydrostatic pressure effects (by contrast to the case of Manson Coffin parameter).

The maps given by Fig.13a and Fig.13b give $F_{C P} /\left\langle F_{C P}\right\rangle$ and $F_{D E} /\left\langle F_{D E}\right\rangle$ values respectively, where the terms in brackets correspond to the average values of the criteria. The criteria mappings are quite similar for AG1 and AG2 free surface. The maxima of the criteria parameters are weak and their localization into the microstructure mimics the strain maps. This means that crack initiation should be difficult and represent the main part of the fatigue life. For AG3a and AG3b, it can be shown from surface mappings observations, that roughness has an influence not only on the cyclic strain amplitude at the bottom of scratches but also on the size and neighbourhood (number of grains involved) of the surface "hot spots". This may have a strong influence on the rate of surface microcracks initiation, on propagation and coalescence and on the probability of overcoming the micro-structural barriers (such as grain boundaries and twins). This leads to shorten the stage II propagation regime. It should be noted that the hot point number is larger for the Dissipated Energy parameter than for the Critical Plan parameter. 


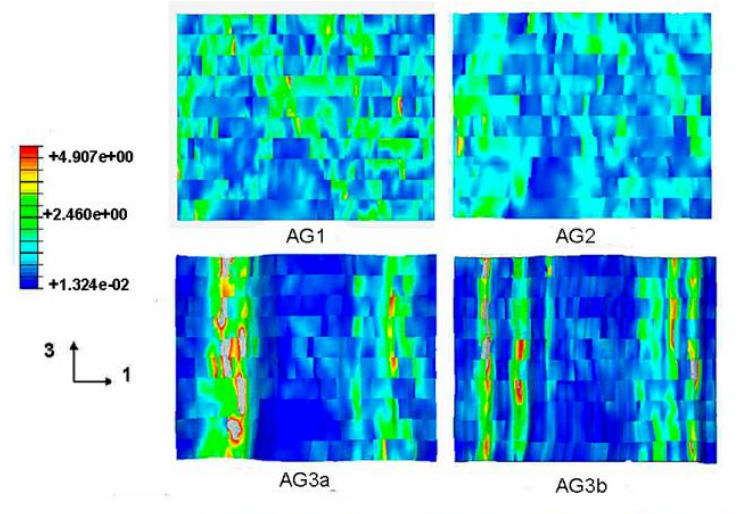

(a)

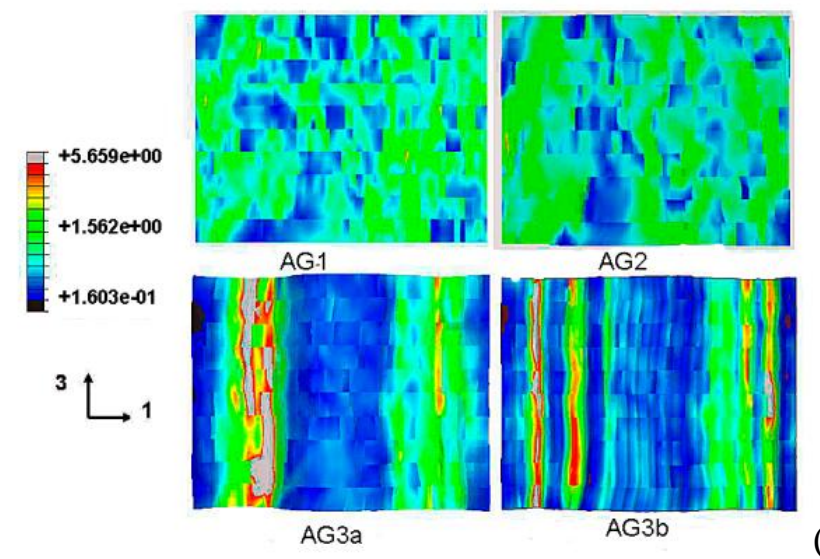

(b)

Fig.13. Mapping of the criterion values for the free surfaces of AG1, AG2, AG3a, AG3b, (a) $F_{C P} /\left\langle F_{C P}\right\rangle$, (b) $F_{D E} /\left\langle F_{D E}\right\rangle$.

According to the Manson-Coffin and Critical-Plane parameters, pre-hardening should increase the fatigue resistance of the aggregate in the stabilized cyclic domain. However, as the stress level is increased at the same time, this effect may not be observed in the real specimen. Before concluding, a detailed study of crack initiation versus stage I and stage II micro-propagation has to be considered. On the free surface, the $\mathrm{F}_{\mathrm{DE}}$ criterion shows the same sensitivity to scratches than the $F_{C P}$ criterion. According to all parameters, the scratches depth and extension (especially when compared to grain size), should play a major role on both microcracks initiation and growth (number of surface grains involved). At the bottom of the scratches, $F_{C P}$ and $F_{D E}$ are 10 times higher than in the bulk of the aggregate or in the smooth (brushed) pre-strained material, leading to the prediction of a much shorter crack initiation life. $F_{M C e q}$ and $F_{C P}$ are based on strain amplitude and give similar predictions. This means that the effect of stress triaxiality in $F_{C P}$ is small, as it can be deduced from the low value of $\alpha$ used for $304 \mathrm{~L}$. It should be noted that the $F_{D E}$ criterion parameter based on energy, is more homogeneously distributed. This means either that the microstructure plays only a minor role into damage prediction, or that this criterion is better suited for a more macroscopic use, as is it often the case for energy based criteria.

\section{Discussion and conclusion}

This paper emphasizes that equivalent strained hot spots are related to the microstructure, to the surface pre-hardening and to the surface finishing. To separate the influence of these parameters, a simulation at the grain scale has been undertaken, thanks to a polycrystal model based on continuum dislocation theory and classical plasticity laws. Implemented in a Finite 
Element code and in the general background of finite transformation, this model can evaluate the local stress and strain fields within the grains of three 304L realistic 3D polycrystalline aggregates. These aggregates obtained by EBSD mapping, represent the initial and prehardened materials and take into account the roughness induced by machining. The boundary conditions and multiaxial loading applied to the aggregates are given by the FE macroscopic modelling of INTHERPOL thermal fatigue test. The material parameters of the polycrystal model are determined by using literature data, dislocation density measurements and different mechanical tests. The introduction of pre-hardening gradient measured on the pipe specimens, is performed using a trapezoidal aggregate, strained to become cubic. This new method leads to an equilibrated stress field. Our aim being to determine damage in the cyclic stabilized regime, all parameters are identified on the stabilized cycle, corresponding to midlife of fatigue curves. Consequently, the validity of the model lies in the stabilized domain, where the hardening variations are weak. This domain corresponds to the main part of fatigue life, during which crack initiation occurs.

Several damage criteria were tested: the Manson-Coffin damage parameter is sensitive to prestraining and roughness but is less sensitive to severe roughness conditions, as it does not take into account the negative effect of stress triaxiality (bottom of scratches) on the damage initiation. For sensitivity to pre-straining, Critical Plane damage parameter behaves similarly to Manson-Coffin parameter, but can also show increased sensitivity to roughness when corrected for stress triaxiality. The Dissipated Energy damage parameter shows a rather poor sensitivity to pre-straining (high stresses, thus low strains) but shows a good sensitivity to roughness when corrected for hydrostatic stress. Manson-Coffin and Critical Plane parameters criteria show that pre-straining should delay crack initiation, but cannot explain the observed fatigue life decreasing for pre-hardened material. However, our model points out that prehardening generates large local stresses, which can explain the fatigue life decrease through larger microcracks openings and shorter microcracks transition from stage I to stage II.

Numerical simulation of fatigue through polycrystal modelling is a promising tool for understanding and predicting the respective roles of complex parameters such as grains orientation, strain hardening gradients, surface roughness and multi-axial loading. This paper is an attempt to show part of the potential of this polycrystalline modelling, which may be an useful tool for damage prediction and fatigue criteria selection in complex mechanical or micro-structural situations.

\section{Acknowledgements}

This work was financially supported by Electricité de France, R\&D.

\section{Reference}

[1] A. Fissolo, C. Gourdin, O. Ancelet, S. Amiable, A. Demassieux, S. Chapuliot, N. Haddar, F. Mermaz, J.M Stelmaszyk, A. Constantinescu, L. Vincent, V. Maillot. Crack initiation under thermal fatigue: An overview of CEA experience. Part I: Thermal fatigue appears to be more damaging than uniaxial isothermal fatigue, Int J Fatigue 31 (2009), 587-600.

[2] A. Fissolo, C. Gourdin, O. Ancelet, S. Amiable, A. Demassieux, S. Chapuliot, N. Haddar, F. Mermaz, J.M Stelmaszyk, A. Constantinescu, L. Vincent, V. Maillot. Crack initiation under thermal fatigue: An overview of CEA experience: Part II (of II): Application of various criteria to biaxial thermal fatigue tests and a first proposal to improve the estimation of the thermal fatigue damage. Int J fatigue 31 52009), 1196-1210.

[2] F. Curtit, J.M. Stephan, INTHERPOL Thermal Fatigue Test. Pressure Vessels and Piping, Denver, 2005, July $17-21$.

[4] A. Le Pécheur, P. Bompard, M. Clavel, F.Curtit, Rey C., J.M. Stephan. Thermal fatigue of austenitic stainless steel: influence of surface conditions. Fatigue Design 2007, Nov 21-22, 2007, Senlis France.

[5] A. Le Pêcheur. Fatigue Thermique d'un acier inoxydable austénitique, influence de l'état de surface, approche multiéchelle, $\mathrm{PhD}$ thesis, Ecole Centrale Paris, 2008 http://tel.archives-ouvertes.fr 
[6] A. Le Pécheur, M. Clavel, F. Curtit, C. Rey, J.M. Stephan, P. Bompard. Influence of surface conditions on fatigue strength through the numerical simulation of microstructure, Revue de Métallurgie. 107 (2010) 477 489.

[7] A. Le Pécheur, F. Curtit, M. Clavel, J.M. Stephan, C. Rey, P. Bompard. Thermo-mechanical FE model with memory effect for 304L austenitic stainless steel presenting microstructure gradient. Int J Fatigue (2012) (http://dx.doi.org/10.1016/j.ijfatigue.2012.05.016)

[8] R.J. Asaro, J.R. Rice. Strain localization in ductile single crystals. J. Mech. Phys. Solids 25 (1877) 309-338.

[9] R.J. Asaro Geometrical effects in the inhomogeneous deformation of ductile single crystals. Acta Metall 23 (1979) 445-453.

[10] R.J. Asaro, A. Needleman. Texture development and strain hardening in rate dependent polycrystals. Acta metal 33 (1985) 923-953.

[11] D. Peirce, R.J. Asaro, A. Needleman. Material rate dependence and localized deformation in crystalline solids. Acta Metall 31 (1983) 1951-1976.

[12] A. Needleman, R.J. Asaro, J. Lemonds, D. Peirce. Finite Element A nalysis of crystalline solids, Computer methods in Applied mechanics and engineering, 52 (1985) 689-708.

[13] G. Sarma, P. Dawson. Texture predictions using a polycrystal model incorporating neighbor interactions. Inter J Plast 1023-1053.

[14] G. Sarma, B. Radhakrishman, T. Zacharia. Finite Element simulations of cold deformation at the mesoscale. Computational Materials Science 12 (1998) 105-123.

[15] D. Raabe, M. Sachtleber, Z. Zhao, F. Rotters, S. Zaefferer. Micromechanical and macromechanical effect in grain scale polycrystal plasticity, experimentation and simulation. Acta Mater, 49 (2001) 3433-3441.

[16] S.R. Kalidindi. Modeling anisotropic strain hardening and deformation texture in low stacking fault energy fcc metals. Int J Plast 17 (2001) 837-860.

[17] G.B. Sarma, B.Radhakrishnan. Modeling microstructural effects on the evolution of cube texture during hot deformation of aluminium. Mater sci eng A, 385 (2004) 91-104.

[18] F. Roters, D. Raabe. Using texture component in crystal plasticity finite element simulations. Int J plast 20 (2004) 339-361.

[19] J.R. Mayeur, D.L. McDowell, R.W. Neu. Crystal plasticity simulations of fretting of Ti-6Al-4V in partial slip regime considering effects of texture. Comput Mater Sci 41 (2008) 356-365.

[20] F.Delaire, J.L Raphanel, C. Rey, Plastic heterogeneities of a copper multicrystal deformed in uniaxial tension : Experimental study and Finite Element Simulations. Acta Mater 48 (2000) 1075-1087.

[21] A. Bhattacharyya, E. El-Danaf, S. Kalidindi, R. Doherty. Evolution of grain scale microstructure during large strain simple compression of polycrystalline aluminium with quasi-columnar grains OIM measurements and numerical simulations, Int J Plast 17 (2001) 537-5673.

[22] F. Barbe, L. Decker, D. Jeulin , G. Cailletaud G. Intergranular and intragranuar behavior of polycrystalline aggregates, Par 1: F.E. model. Int J Plast, 17 (2001) 513-536.

[23] Barbe F., Forest S., Cailletaud G. Intergranular and intragarnular behavior of polycrystalline aggregates, Part 2: Results. Int J Plast 17 (2001) 537-563.

[24] T. Hoc, C. Rey, J.L. Raphanel. Experimental and numerical analysis of localization during sequential test for an IF-Ti steel, Acta Mater (2001) 1835-1846.

[25] P. Erieau, C. Rey. Modelling of deformation and rotation bands and of deformation induced grain boundaries in IF steel aggregate during large plane strain compression. International Journal of Plasticity Int J Plast 20 (2004) 1763-1788.

[26] A. Ma, F. Roters, D. Raabe. On the consideration of interaction between dislocations and grain boundaries in crystal plasticity finite element modeling. theory, experiments and simulation. Acta Mater 54 (2006) 2169-2179.

[27] H.W. Li, H. Yang, Z.C. Sun. A robust integration algorithm for implementation rate dependent crystal plasticity into explicite finite element method. Int J plast 24 (2008) 267-288.

[28] J.R. Mayeur, D.L. McDowell. A three-dimensional crystal plasticity model for duplex Ti-6Al-4V. Int. J; Plast. 23 (2007) 1457-1485.

[29] M, Libert, L. Vincent, B. Marini, C. Rey, Temperature dependant polycrystal model. Application to bainitic steel under tria-xial loading in the ductile brittle transition. Int. J. Sol. Struct 48 (2011) 2196-2208.

[30] D. Cédat, O. Fandeur, C. Rey, D. Raabe. Polycrystal model of the mechanical behavior of a MoTiC30vol.\% metal-ceramic composite using a 3D microstructure map obtained by a dual beam FIB-SEM. Acta Mater 60 (2012) 1623-1632.

[31] N.A. Fleck, J.W. Hutchinson. Strain gradient plasticity. J. Mech Phys Solids 33 (1997) 295-361.

[32] A. Beaudoin, A. Acharya, S. Chen, D. Korzekwa, M. Stout. Consideration of grain-size effect and kinetics in the plastic deformation of metal polycrystals. Acta Mater 48 (2000) 3409-3423.

[33] A. Acharia , J.L. Bassani. Lattice incompatibility and gradient theory of crystal plasticity. J Mech Phys Solids 48 (2000) 1565-1595. 
[34] E.P. Busso, F.T. Meissonnier, N.P. O’Dowd, Gradient-dependent deformation of two-phase single crystals. J. Mech Phys solids 48 (2000) 2333-2361.

[35] N.A. Fleck, J.W. Hutchinson, a reformulation of strain gradient plasticity. Adv Applied Mech 49 (2001) 2245-2291.

[36] A. Ma, F. Roters, D. Raabe. A dislocation density based constitutive model for crystal plasticity FEM including geometrically necessary dislocations. Acta Mater 54 (2006) 2181-2194.

[37] A. Ma, F. Roters, D. Raabe, A dislocation density based on constitutive law in BCC materials in crystal plasticity FEM. Computation Material Science. 39 (2007)91-95.

[38] C.H. Goh, D. L. Mc Dowell, R.W. Neu. Plasticity in polycrystalline fretting fatigue contacts. J. Mech Phys Solids, 54 (2006) 340-367.

[39] F.P.E. Dunne, D. Rugg, A. walker. Lenghscale-dependent, elastically anisotropic, physically-based hcp crystal plasticity: Application to cold-dwell fatigue in Ti alloys. Int J Plast 23 (2007) 1061-1083.

[40] G. Venkatramani, S. Gosh, M. Mills. A size dependant crystal plasticity finite-element model for creep and load shedding in polycrystalline titanium alloys. Acta Mater 55 (2007) 3971-3986.

[41] M. Zhang, J. Zhang, D.L. McDowell. Microstructure-based crystal plasticity modeling of cyclic deformation of Ti-6Al-4V; Int J Plast 23 (2007) 1328-1348.

[42] F. Bridier, D. McDowell, P. Villechaise, J. Mendez. Crystal Plasticity modeling of slip activity in Ti-6Al4V under high cycle fatigue loading. Int J Plast 25 (2009) 1066-1082.

[43] M. Zhang, F. Bridier, P. Mendez, D.L. McDowell. Simulation of slip band evolution of variable amplitude loading in duplex Ti-6Al-4V. Acta Mater 58 (2010) 1087-1096.

[44] M. Zhang, F. Bridier, P. Villechaise, J. Mendez, D.L. McDowell. Simulation of slip band evolution in duplex Ti-6Al-4V. Acta Mater. 58 (2010) 1087-1096.

[45] J.R. Mayeur, D.L. McDowell, D. J. Bammann. Dislocation-based micropolar single crystal plasticity: comparison of multi-and single-criterion theories. J Mech Phys Solids 59 (2011) 398-422.

[46] F. Roters, P. Eisenlohr, L. Hantcherli, D. Tjahjanto, T.R. Bieler, D. Raabe. Overview of constitutive laws, kinematics, homogeneization and multiscale methods in crystal plasticity finite element modelling: theory, experiments, applications. Acta Mater.58 (2010) 1152-1211.

[47] C. Teodosiu., J.L. Raphanel., L.Tabourot., 1993. Finite element simulation of the large elastoplastic deformation of multicrystals. MECAMAT'91, Teodosiu, Raphanel \& Sidoroff (eds) @ Balkema, Rotterdam, 153-160.

[48] L. Tabourot, M. Fivel, E. Rauch. Generalised constitutive laws for FCC single crystals. Mat Sci Eng A, 234-236, (1997) 639-642.

[49] P. Franciosi, M. Berveiller, A. Zaoui , Latent hardening in Copper and Aluminium Single Crystals. Acta Metall. 28 (1980) 273-283.

[50] Armstrong, Frederick. A mathematical representation of multiaxial baushinger effect. CEGB Report RD/B/N731, Berkeley, Nuclear laboratories (1966).

[51] X. Feaugas, C. Gaudin. Rachetting process in the stainless steel AISI 316L at $300 \mathrm{~K}$ : and experimental investigation. Int J Plast, 20 (2004) 643-662.

[52] P. Evrard, V. Aubin, P. Pilvin, S. Degallaix, D. Kondo. Implementation and validation of a polycrystalline model for a bi-phased steel under non proportional loading. Mech Res Com 5 (2008) 336-343.

[53] P. Evrard, V. Aubin, S. Degallaix, D. Kondo, Formulation of a new single law for modelling the cyclic softening, Mechl Res Com 35 (2008) 589-594.

[54] Y. Li, V. Aubin, C. Rey, P. Bompard. Polycrystalline numerical simulation of variable amplitude loading effects on cyclic plasticity and microcrack initiation in austenitic steel 304L. Int.J. Fat 42 (2012) 71-81.

[55] J. Schwartz. Approche non locale en plasticité cristalline : application à l'étude du comportement mécanique de l'acier AISILN en traction simple et en fatigue olygocyclique. (2011) Thèse de Doctorat, Ecole Centrale Paris. http://tel.archives-ouvertes.fr

[56] A. Fatemi, D.F. Socie. A critical plane approach to multiaxial fatigue damage including out of phase loading. Fat Fract Eng Mater Struct 11 (1988) 3 149-65.

[57] D. Socie. Critical plane approaches for multiaxial fatigue damage assessment, in: McDowell/Ellis (Eds), Advances in multiaxial fatigue. ASTM STP 1191, (1993), pp. 7-36.

[58] J. Park, D. Nelson. Evaluation of an energy-based approach and critical plane approach for predicting constant amplitude multiaxial fatigue life. Int J Fat 22 (2000) 23-39.

[59] S. Amiable, S. Chapuliot, A. Constantinescu, A comparison of life time prediction methods for a thermal fatigue experiment, Inter J. Fat. 28 (2006) 692-706.

[60] S. Amiable, Prediction de la duréee de vie des structures sous chargement de fatigue thermique, Thèse de Doctorat, Université de Versailles 2006. 